www.jcmtjournal.com

Open Access

\title{
Immunological aspect of the liver and metastatic uveal melanoma
}

\author{
Mizue Terai, Michael J. Mastrangleo, Takami Sato \\ Department of Medical Oncology, Sidney Kimmel Medical College, Thomas Jefferson University, Philadelphia, PA 19107, USA.
}

Correspondence to: Dr. Mizue Terai, Department of Medical Oncology, Sidney Kimmel Medical College, Thomas Jefferson University, 1015 Walnut Street, 1024 Curtis Building, Philadelphia, PA 19107, USA. E-mail: mizue.terai@Jefferson.edu

How to cite this article: Terai M, Mastrangleo MJ, Sato T. Immunological aspect of the liver and metastatic uveal melanoma. J Cancer Metastasis Treat 2017;3:231-43.

\begin{tabular}{l} 
Article history: \\
Received: 1 Jun 2017 \\
Accepted: 23 Oct 2017 \\
Published: 31 Oct 2017 \\
\hline Key words: \\
Uveal melanoma, \\
metastasis, \\
liver, \\
liver microenvironment, \\
immunotherapy \\
\end{tabular}

\section{INTRODUCTION}

Uveal melanoma (UM) originates from the uveal tract of the eye (iris, ciliary body, and choroid). The estimated incidence of UM is 5 per million in the United States, and between 2 to 8 per million in Europe ${ }^{[1]}$. Despite shared embryologic origin, UM differs from the cutaneous melanoma in biological behavior, epidemiology, prognostic features, and molecular profiles ${ }^{[2,3]}$. Previous

\begin{abstract}
Uveal (eye) melanoma is the most common primary eye malignancy in adults. Despite optimal treatments for primary uveal melanoma, up to $50 \%$ of patients subsequently develop systemic metastasis, often in the liver. Once hepatic metastasis develops, the survival of patients is generally short and currently available treatments fail to show meaningful improvement of survival. Recent development of immune checkpoint blockades revolutionized immunotherapy for metastatic cutaneous (skin) melanoma. Unfortunately, metastatic uveal melanoma is unresponsive to this approach, thus there is an unmet need to improve the treatment of metastatic uveal melanoma. One unique characteristic of uveal melanoma is that the majority of metastases first develop in the liver. The liver is highly specialized in development of immune tolerance to food-derived antigens and consequently serves a unique function in the immune system. Understanding the mechanisms by which the liver orchestrates immune-related responses is important to the development of an effective immunotherapy for hepatic metastases such as metastatic uveal melanoma. In this review article, the authors overview the immunological aspects of the liver and discuss approaches to improve immunotherapy for metastatic uveal melanoma.
\end{abstract}

investigators have identified categories of patients with a higher risk of systemic recurrence. Such risk factors include: large tumor size, epithelioid cell type, extrascleral extension, loss of chromosome 3 (monosomy 3 ), and chromosome $8 q$ amplification ${ }^{[4]}$. Up to $50 \%$ of patients with UM develop metastases within 10 years of diagnosis ${ }^{[1]}$. UM disseminates homogeneous, as there is no significant lymphatic drainage from the eye. The most common sites of metastasis are the liver (80$90 \%)$, then lung and bone ${ }^{[1,5]}$. Hepatic metastasis is an

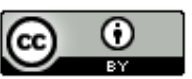

This is an open access article licensed under the terms of Creative Commons Attribution 4.0 International License (https://creativecommons.org/licenses/by/4.0/), which permits unrestricted use, distribution, and reproduction in any medium, as long as the original author is credited and the new creations are licensed under the identical terms.

For reprints contact: service@oaepublish.com

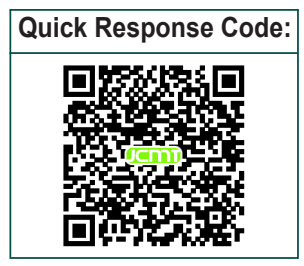


important determinant of clinical course and survival. After development of hepatic metastasis, the median survival of patients is reported to be 6 to 12 months ${ }^{[2]}$.

The liver copes with the bacterial pathogens, toxins, and food antigens transported through the portal vein from the gastrointestinal tract. The immune cells in the liver serve diverse functions ranging from immunity against bacteria and tolerance to food antigens.

Circulating tumor cells (CTCs) that enter the liver encounter a unique immune system. Interaction between the liver immune system and cancer cells provide a complex tumor microenvironment. Newly developed immunological treatment strategies such as immune checkpoint blockade have appreciably improved the survival of non-hepatic metastatic cutaneous melanoma patients; however, response of hepatic metastases is less robust. Likewise, UM patients with hepatic metastases have not derived meaningful survival benefit from these immunetherapies.

In this review article, we first overview the immune microenvironment of primary UM and that of the liver. We then summarize ongoing immunotherapies against metastatic UM and discuss possible approaches to improve the efficacy of immunotherapy against metastatic UM.

\section{IMMUNOLOGICAL MICROENVIRONMENT OF PRIMARY UVEAL MELANOMA}

The eye is considered an immune-privileged organ. It has a unique ability to defend against uncontrolled inflammation that could damage sight. Anatomical constraints to the development of an immune response in the eye include the absence of lymphatics that limit the traffic of immune cells to the eye. Immune cells that enter the eye encounter immunosuppressive factors such as transforming growth factor beta (TGF- $\beta$ ), $\alpha$-melanocyte stimulating hormone (MSH), retinoic acid (RA), and indoleamine 2, 3-dioxygenase (IDO) ${ }^{[6]}$. These factors suppress $\mathrm{T}$ cell proliferation and effector function, and could induce immunosuppressive regulatory $T$ (Treg) cells.

A lymphocyte-rich tumor microenvironment generally indicates a good prognosis in various types of cancer. Paradoxically, in UM high densities of immune cells are associated with poor prognostic factors. Primary UMs with monosomy 3 , in comparison to those with disomy 3 , are associated with a more vigorous inflammatory response, with infiltration by a variety of immune cells, including $\mathrm{CD}^{+}, \mathrm{CD}^{+}, \mathrm{CD}^{+}{ }^{+} \mathrm{CD} 8{ }^{-} \mathrm{Foxp}^{+}{ }^{+} \mathrm{T}$ cells and $\mathrm{CD} 8^{+} \mathrm{CD} 163^{+} \mathrm{M} 2$ macrophages ${ }^{[7,8]}$. Infiltration of immune cells occurs more frequently in epithelioid-celltype UM. An increased number of macrophages were associated with epithelioid tumor cells $(P=0.025)$, heavy pigmentation $(P=0.001)$, and high microvascular density $(P=0.001)$. The 10 -year melanoma-specific mortality rate increased with increasing numbers of macrophages ( 0.10 for low vs. 0.57 for high numbers, $P=0.0012)^{[9]}$. It has been reported that Treg cells are recruited into tumors by chemokines, CCL17 and CCL22 that are produced by M2 macrophages. Furthermore, tumor-produced CCL2 and CCL22 have a role not only in attracting tumor-promoting macrophages, but also in promoting their survival and M2 polarization ${ }^{[7]}$.

While UM cells possess tumor-associated antigens and tumor-infiltrating $\mathrm{CD}_{4}^{+}$and $\mathrm{CD} 8^{+}$cells are present in the primary UM, Treg cells are also present in the tumor. One study has identified that the frequency of $\mathrm{CD}^{+}$, forkhead box P3 (FoxP3) ${ }^{+}$Treg cells within primary UM is correlated with the development of systemic metastasis ${ }^{[10]}$. The presence of Treg cells and cyclooxygenase-2 expression in the tumors is especially correlated with poor prognosis ${ }^{[10]}$. In terms of the role of NK cells in primary UM, down-regulation of HLA class I, which is a common mechanism for evading $\mathrm{CD} 8^{+}$cells, renders tumors more susceptible to NK cell-mediated lysis. However, while the NKG2D ligands (MIC-A and B) are expressed by $50 \%$ of primary UM, none of the metastases express these ligands, indicating that metastatic UM might not be controlled by NK cells ${ }^{[11]}$.

The mechanism of inflammatory cell infiltration to the primary UM and the reason for contradictory clinical outcomes remains speculative. Accumulative evidence indicates that tumor-microenvironment crosstalk facilitates cancer cells to modulate the inflammatory response. Cancer cells interact with both the innate and the adaptive immune systems and skew the acquired $\mathrm{T}$ cell response from the $\mathrm{T}$ helper 1 (TH1) type to the TH2 type. Cancer cells also skew the phenotype of macrophages and neutrophils to a type 2 differentiation and attract myeloid-derived suppressor cells (MDSCs) as well as Treg cells to tumor sites ${ }^{[12]}$. UM cells may utilize these immune cells for their survival and protection from immunological attack. It is possible that UM cells already induced tolerance against them when they left from the eye. Immuno-modulatory microenvironment in the liver could further protect escaped UM cells from systemic immune surveillance.

\section{MECHANISMS OF METASTASIS TO THE LIVER}

The mechanisms for development of metastases in 
the liver are still highly speculative. It is assumed that multiple factors contribute to development of metastasis and growth of UM cells in the liver. The proposed mechanisms are summarized as follows.

\section{Slow hepatic blood circulation}

The liver sinusoids are located at a confluence of arterial (hepatic artery) and venous (portal vein) blood, mixing the oxygen-rich blood from the hepatic artery and the nutrient-rich blood from the portal vein. They are a type of capillary-like blood vessels with fenestrated, discontinuous endothelium. Slow flow in the liver sinusoids maximizes the contact between hepatic cells and pathogenic molecules to filter them prior to circulation. The slow and tortuous sinusoidal blood flow can trap UM cells in the liver ${ }^{[13,14]}$.

\section{Interaction between chemo-attractants and their receptors}

The chemokines produced in the liver might attract UM cells to the liver and interact with chemokine receptors on their surface. A typical example is the interaction between CXCR4 and its ligand CXCL12 that is rich in the liver ${ }^{[15]}$. Primary UM cell lines express CXCR4. Blockage of CXCR4 on UM significantly reduced migration to human liver extract ${ }^{[16]}$. An alternative explanation for chemokine-related liver tropism is the loss of chemokine receptors in the liver. It has been reported that extracts from the liver down-regulated the expression of CXCR4 and CCR7 on primary UM cell lines ${ }^{[16]}$. Retention of UM cells in the liver may not solely be related to a chemokine gradient toward the liver, but could also be related to the loss of chemokine receptors once melanoma cells reach the liver.

Another example is c-Met, a receptor for hepatocyte growth factor (HGF). c-Met-expressing UM cells interact with HGF produced in the liver ${ }^{[14]}$. Primary UM cells that metastasized had higher levels of c-Met expression than tumors that did not metastasize. The expression of c-Met in the primary UM specimens significantly increased the risk of subsequent liver metastasis $^{[14]}$.

\section{Growth factors rich in the liver}

The insulin-like growth factor-1 (IGF-1) plays a major role in tumor transformation, maintenance of malignant phenotype, promotion of cell growth, and prevention of apoptosis. It is mainly produced in the liver. High expression of IGF-1 receptor (IGF-1R) has been detected in UM hepatic metastasis specimens ${ }^{[17]}$. The association between the expression of IGF-1R on tumors and the progression of UM also has been reported ${ }^{[18]}$. Additionally, HGF could facilitate the growth of c-Met-expressing UM cells in the liver.

\section{Chromosomal and genetic abnormalities}

UM has unique genetic abnormality profiles compared to cutaneous melanoma (CM). Mutation of BRCA1associated protein 1 (BAP1), located on chromosome $3 \mathrm{p} 21$, was frequently identified in metastatic $\mathrm{UM}^{[19-21]}$. Particularly, it was reported that BAP1 mutation in UM cells may cause the liver tropism ${ }^{[22]}$. However, this might be an over-simplified explanation for the liver tropism as a certain fraction of metastatic UM retained their BAP1 expression and monosomy 3 is not always seen in hepatic metastasis. Polysomy $8 q$ is rather a common feature of metastatic UM, and the role of this chromosomal abnormality on hepatic metastasis should be further explored ${ }^{[23,24]}$.

\section{The expression of adhesion molecules in the sinusoid}

Vascular cell adhesion molecule-1 (VCAM-1) is expressed on sinusoidal endothelial cells and might trap tumor cells in slow blood flow ${ }^{[13,25]}$. VCAM-1 is expressed on endothelial cells under inflammatory conditions, and mediate rolling and adhesion of various subsets of leukocytes as well as tumor cells for the recruitment and settlement of these cells from the blood stream. In animal models, partial-hepatectomy induced expression of inflammatory cytokines such as tumor necrosis factor (TNF)- $\alpha$, interleukin (IL)- $1 \beta$ and IL- 6 as well as the expression of VCAM-1 and facilitated liver metastasis ${ }^{[26]}$. Endothelial cell expression of VCAM-1 showed adhesion of human malignant melanoma cells that expressed very late activation antigen-4 (VLA-4) on their surface ${ }^{[27]}$.

\section{Angiogenesis factors rich in the liver}

IL-8 and vascular endothelial growth factor (VEGF) are rich in the liver and could promote the angiogenesis of tumor in the liver microenvironment ${ }^{[28]}$. Hepatic stellate cells (HSCs) in the tumor stroma predominantly produce IL-8, and neutralizing IL-8 with antibody dramatically reduces angiogenic effects ${ }^{[28]}$. IL-8 also induces the expression of VEGFR2 and VEGF on endothelial cells through NFkB activation, and mediates autocrine and paracrine stimulation of vascular endothelium.

\section{Immuno-modulatory microenvironment}

As stated in the following section, the liver is considered to be an immuno-modulatory organ ${ }^{[29,30]}$ and this immunologically complex microenvironment could promote tumor metastasis and growth in the liver.

\section{IMMUNOLOGICAL ASPECTS OF THE LIVER IMMUNE MICROENVIRONMENT}

The liver has acomplex immune microenvironment. It is continually exposed to foreign pathogens such 


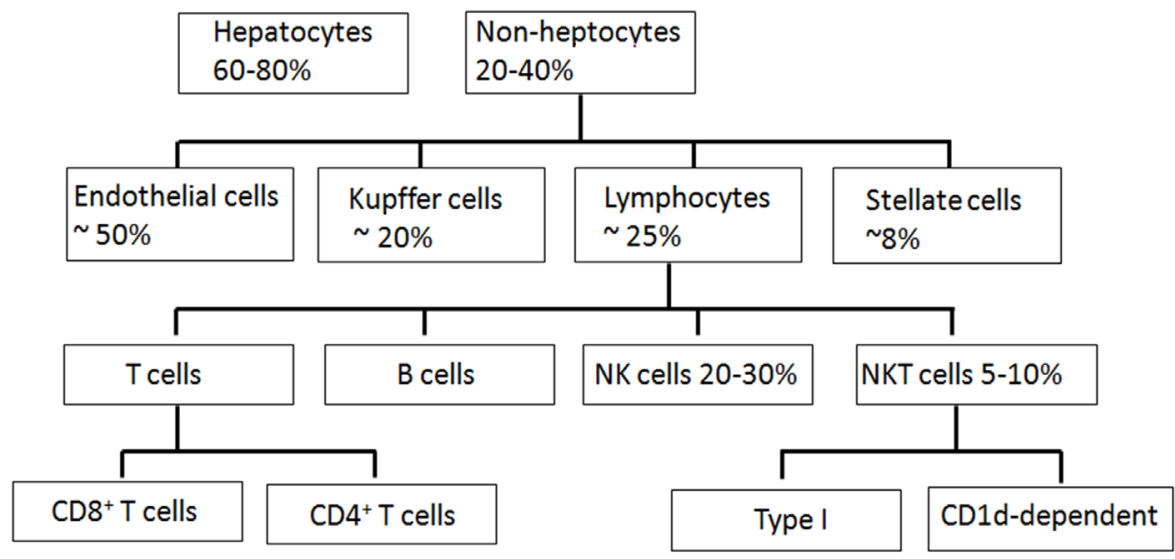

Figure 1: Cell population in the liver. The percentages indicate the estimated frequency of each population relative to the total number of parenchymal and non-parenchymal cells in the normal liver

as food antigens and low levels of endotoxin, many of which are derived from the gut. The local immune system must constantly provide secure mechanisms to eliminate those pathological antigens and toxins while it maintains tolerance to dietary antigens. In addition, the liver is subject to invasion by infectious pathogens from intestinal mucosa and the liver immune system must eliminate these infectious pathogens to protect the host from systemic infection. Thus, liver immunity exists in a delicate balance between the tolerance of essential elements and the defense against pathological agents.

\section{RESIDENTIAL CELLS IN THE LIVER}

Homeostatic immune microenvironment is tightly controlled by various residential non-immune cells and immune cells in the liver. There is a diverse population of residential cells in the liver, including the liver sinusoidal endothelial cells (LSECs), Kupffer cells (KCs), HSCs, and hepatocytes [Figure 1].

\section{LSECs}

LSECs separate the underlying hepatocytes from the blood in the sinusoidal lumen by the space of Disse [Figure 2]. LSECs do not have a basement membrane. This structure allows for the quick exchange of molecules between blood and hepatocytes. HSCs reside in the space of Disse. The lymph is collected from this space and flows into lymphatic vessels that run into the draining lymph nodes via portal tracts. LSECs have the capacity for endocytosis and phagocytosis through receptors, and present antigens as antigen-presenting cells (APCs) $)^{[29]}$. LSECs are efficient in cross-presentation of antigens, allowing both $\mathrm{CD}^{+}$and $\mathrm{CD} 8^{+} \mathrm{T}$ cells to be activated by blood-derived antigens. Upon stimulation, LSECs secrete chemokines, CXCL9 and CXCL10, and recruit lymphocytes. On the other hand, LSECs are able to express PD-L1 triggered by cognate interaction with activated $\mathrm{T}$ cells for elimination of these $\mathrm{T}$ cells. In contrast, the exposure to soluble molecules such as $\mathrm{IL}-10$ and prostaglandin E2 (PGE2) derived from KCs can reduce the expression of major histocompatibility complex (MHC) and costimulatory molecules on LSECs that promotes immune tolerance in the liver ${ }^{[30]}$.

\section{KCs}

KCs comprise $80-90 \%$ of all tissue macrophagesin the body and account for $20 \%$ of non-hepatocytes in the liver ${ }^{[29]}$. Granulocyte macrophage colony stimulating factor (GM-CSF) appears to be most important for the development of mature $\mathrm{KCs}^{[31]}$. Large $\mathrm{KCs}$ are predominantly located in the region of liver acini near the portal triads and have higher lysosomal enzyme activities and a greater phagocytic capacity. The large KCs also produce TNF- $\alpha$, PGE2, IL-10 and IL-1, while small KCs near the central veins produce high level of nitric oxide (NO) ${ }^{[32]}$.

One of the primary function of KCs is to discriminate "self" from "non-self" particles, playing a prominent role as APC as well as a scavenger of microorganisms. One of the molecules that recognizes "self" and "nonself" is Dectin-2, a C-type lectin receptor of the innate immunity receptor family. It is known to recognize high-mannose carbohydrate structures present on bacteria and fungi. This receptor also recognizes tumor cells. Once tumor cells are recognized via Dectin-2, KCs increase phagocyte activity against tumor cells, which contributes to the suppression of metastasis in the liver ${ }^{[33]}$

\section{HSCs}

Eighty percent of total body vitamin $A$ is stored in HSCs as intra-cytoplasmic lipid droplets. Upon their activation, HSCs metabolize vitamin A and all-trans 


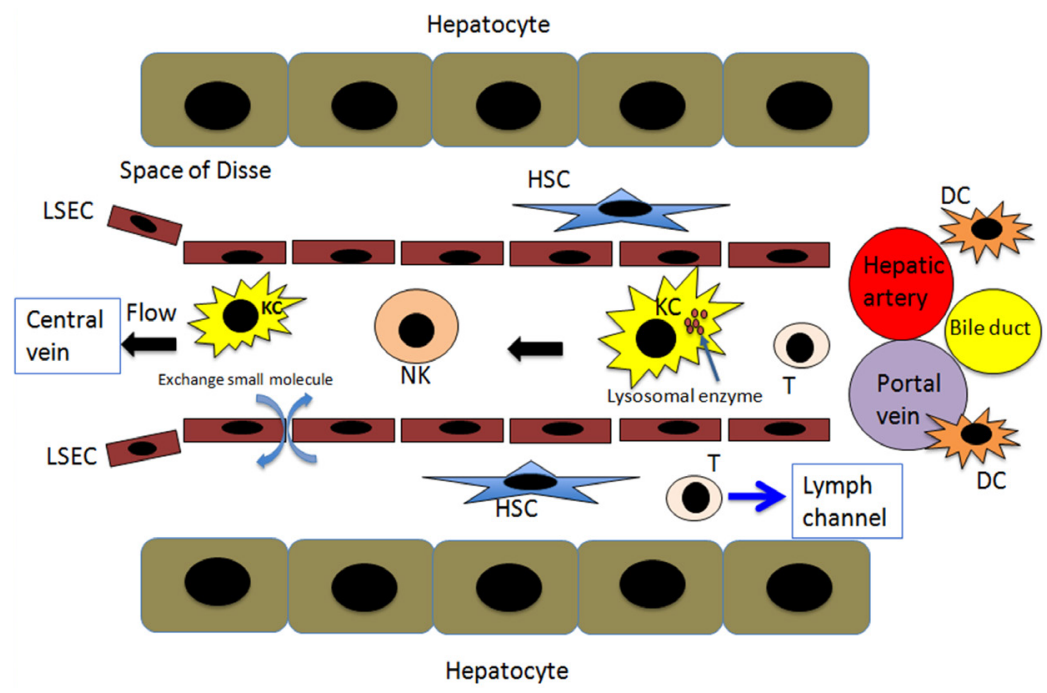

Figure 2: Immune microenvironment in the liver. Liver sinusoids are lined by a fenestrated monolayer of LSECs. HSCs reside in the space between hepatic cells and LSECs, called the Space of Disse. Blood flow in the Space of Disse goes toward the lymphatic vessels that run through the portal tracts to the draining lymph nodes. Blood from the hepatic artery and the portal vein goes through capillary-like vessels, called sinusoids, to the central vein. Dendritic cells are mainly located in the portal tracts. Large Kupffer cells, which have higher lysosomal enzyme activity, are located predominantly in the periportal region. Smaller Kupffer cells are located more close to the central vein. NK cells and T cells patrol the sinusoid. Hepatic NK cells are found in the sinusoidal space, while CD3 cells are mainly present in the periportal area. LSEC: liver sinusoidal endothelial cell; KC: Kupffer cell; HSC: hepatic stellate cell; DC: dendritic cell; NK: natural killer cell; T: T cell

retinoic acid, and are differentiated into myofibroblasts (MFs), which produce extracellular matrix and play a central role in hepatic fibrosis and cirrhosis. TNF- $\alpha$, IL- 6 and TGF- $\beta$ promote activation and proliferation of HSCs to produce different extra-cellular matrix (ECM) components including $\alpha$-smooth muscle actin ( $\alpha$-SMA) and type I collagen for tissue remodeling ${ }^{[34]}$. The activation of HSCs from their resting/quiescent state to a profibrotic state triggers production of HGF, which results in recruitment of c-Met-expressing cells. It also contributes to proliferation of c-Metexpressing tumor cells and prevents apoptosis ${ }^{[14,30,35]}$. Furthermore, secretion of IL-8 from HSCs contributes to tumor angiogenesis, which facilitates the growth of metastases in the liver ${ }^{[28,36]}$.

\section{Hepatocytes}

Hepatocytes comprise $80 \%$ of all liver cells. Hepatocytes express low levels of MHC class I and co-stimulatory molecules. However, under inflammatory conditions some hepatocytes express $\mathrm{MHC}$ class $\|^{[30]}$ and initiate an adoptive immune response. Hepatocytes produce IL-6 upon stimulation by HGF, lipopolysaccharide, or bacterial hepatotoxins ${ }^{[37]}$.

\section{CIRCULATING IMMUNE CELLS IN THE LIVER}

Immune homeostasis is dependent on the ability of the immune system to respond to pathogens. A variety of circulating immune cells in the liver interact with residential liver cells and modulate immune responses in the liver as well as in the peripheral sites. These populations of immune cells reside in various locations in the liver ${ }^{[38]}$.

\section{NK cells}

NK cells represent only a small fraction of circulating lymphocytes, but account for up to $50 \%$ of lymphocytes in the liver. It has been reported that the human liver contains two NK cell subsets: conventional NK cells (cNK), which circulate freely, and liver-resident (Ir) NK cells. There are two non-overlapping NK cell populations in human IrNK cells: CD49a (integrin $\alpha 1)^{+}$ NK cells and Eomeshi (largely CD56 bright and CXCR6 ${ }^{+}$) NK cells ${ }^{[39]}$. Eomes ${ }^{\text {hi }}$ Tbet $^{\text {to }}$ NK cells account for $50 \%$ of human liver NK cells and they reside in sinusoidal space. This type of NK cells is completely absent in peripheral circulation. Eomes ${ }^{\text {hi }}$ IrNK express fewer receptors for human targets, suggesting that they would recognize non-human targets such as bacteria or bacterial products. In contrast, CD49a $\mathrm{NK}^{+}$cells are mainly found in the parenchyma and express cytotoxic effector molecules and receptors for MHC class I; thus, it seems likely that they recognize and kill virally infected or cancerous cells. It has been suggested that these IrNK cells have immune memory against specific antigens ${ }^{[39]}$.

\section{NKT cells}

NKT cells are activated by self- or microbial-lipid antigens, or by signaling through toll-like receptors (TLR), and act as a bridge between innate and adaptive 
immunities. Following activation, NKT cells rapidly secrete either pro-inflammatory or anti-inflammatory cytokines and chemokines, and thereby determine the direction for subsequent immunity or tolerance.

Type I invariant NKT cells expressing specific T cell receptors (TCRs) comprise $95 \%$ of liver NKT cells, while type II NKT cells expressing diverse TCRs make up less than $5 \%$ of them. NKT cells recognize non-peptide antigen targets such as lipid and glycolipid components. They are activated by IL-12 or by interaction between NKG2D and its ligands on target cells. The role of NKT cells in cancer is rather controversial. In patients with hepatocellular carcinoma (HCC), CD4 ${ }^{+}$Va24/VB11 type I NKT cells secreting Th2 cytokines, accumulated in tumor sites, and inhibited tumor-specific $\mathrm{CD}^{+} \mathrm{T}$ cell responses ${ }^{[40]}$.

\section{T cells}

The normal resident lymphocytes of the human liver consist of more $\mathrm{CD} 8^{+} \mathrm{T}$ cells relative to $\mathrm{CD} 4^{+} \mathrm{T}$ cells. Circulating $T$ cells pass through the liver sinusoids and can interact with KCs and LSECs. Antigens that are expressed in the liver might be taken up by immature dendritic cells (DCs) and then presented to $\mathrm{CD}^{+}$and $\mathrm{CD}^{+} \mathrm{T}$ cells either in lymphoid-tissue aggregates in the portal tracts or in secondary lymphoid tissues. Alternatively, antigens might be presented in situ by LSECs, KCs and, possiblyby hepatocytes. The outcome of antigen recognition by $T$ cells in the liver could induce the proliferation of $T$ cells or activation-induced T-cell apoptosis. Antigen recognition could also result in immune deviation to a suppressive or regulatory phenotype.

The determination of outcome depends on upregulation and expression of an extensive panel of T-cell interacting molecules including intercellular adhesion molecule 1 (ICAM1), MHC class II molecules, VCAM1, co-stimulatory molecules of the B7 family, and CD95 (FAS). These molecules might also modify cell trafficking, priming, and the induction of tolerance.

In general, with the production of immune modulatory cytokines such as IL-10 and TGF- $\beta$, the antigenpresentation by LSECs and many DCs in the liver is biased strongly towards the induction of $\mathrm{CD}^{+} \mathrm{T}$ cells with a regulatory phenotype ${ }^{[41]}$, whereas both $C D 8^{+} T$ cells that are activated systemically and naive $\mathrm{CD} 8^{+}$ $T$ cells that first encounter antigen in the liver are predisposed to undergo apoptosis. The liver sequesters activated $T$ cells in an antigen-independent manner, and the high apoptotic rate of such cells has given rise to the idea that the liver might be a "graveyard" for systemic $T$ cells. Activated antigen-specific $T$ cells expressing PD-1 interact with PD-L1 on LSECs to become tolerogenic or apoptotic ${ }^{[42]}$. Activated $T$ cells have been shown to be short-lived in the liver ${ }^{[29]}$.

It is of note that tryptophan 2,3-dioxygenase (TDO) is predominantly expressed in the liver. In contrast, indoleamine 2,3-dioxygenase (IDO) is found in many tissues and induced by interferon (IFN)- $\mathrm{Y}$. TDO and IDO are responsible for metabolism of tryptophan (TRP). The metabolite of TRP, kynurenine (KYN), binds to the aryl hydrocarbon receptor (AHR) on $T$ cells to suppress their activity. Effector $T$ cells are particularly sensitive to low TRP levels. Local depletion of TRP suppresses $T$ cell proliferation and induces cell death ${ }^{[43]}$. AHR activation reportedly induces differentiation of Treg cells ${ }^{[44]}$.

\section{INTERACTIONS BETWEEN CTCS AND LIVER MICROENVIRONMENT}

CTCs can enter the liver through both the hepatic artery and portal vein. CTCs in the liver encounter various populations of residential cells that are specialized to carry out various immunological functions in the liver. Actual mechanism of establishment and progression of hepatic metastasis in UM are mostly speculative. Based on the published literatures ${ }^{[13,29,30,41,45-49]}$ and our limited institutional experience, we propose the following twophase growth model for metastatic UM in the liver.

\section{Microvascular phase}

This phase starts with tumor cell arrest in the sinusoidal space. The final fate of surviving tumor cells can be determined by the interactions between tumor cells and immune cells. These interactions can lead to tumor cell death, or the growth of the tumor in the liver. Obstruction of the sinusoidal vessels by clusters of CTCs can result in transient blockade of blood flow and ischemia. This could result in tumor cell destruction caused by mechanical stress and deformation-associated trauma. Additionally, VCAM-1 expression on LSEC increases and traps melanoma cells that enter the liver ${ }^{[50]}$. It was reported that VCAM-1 expression on LSEC increased significantly within $24 \mathrm{~h}$ of melanoma cell entry into the liver ${ }^{[50]}$, and blocking VCAM-1 by antibodies decreased microvascular retention of tumor cells and metastasis. Tissue ischemia induces the local release of $\mathrm{NO}$ and reactive oxygen species, and kills tumor cells.

LSEC and KCs are likely to be the first resident cells that CTCs encounter in the liver. The tumor cells can be eliminated by local, tumoricidal KCs. KCs can also activate other innate immune response cells such as NK cells, NKT cells, and neutrophils. NK cells can mediate antitumor cytotoxicity by secreting perforin/granzyme or through 
CD95/CD95L pathway. Cytokines and chemokines such as TNF- $\alpha$, IL-8, and CXCL10 can activate resident tumoricidal macrophages, as well as recruit host immune cells with anti-tumor activities ${ }^{\left[{ }^{[1]}\right]}$ [Figure $\left.3 \mathrm{~A}\right]$.

\section{Growth phase}

While an efficient first line defense can defeat some CTCs trapped in the liver, local inflammatory response can also promote tumor cell adhesion to LSECs and subsequent trans-endothelial migration of tumor cells, which results in escape from the cytotoxic resident KCs and NK cells. IL-10 production from KC or LSECs enhances the expression of the chemokine receptor CCR5, but down-regulates CCR7 expression by DCs thus preventing their homing to the secondary lymphoid tissue ${ }^{[41]}$. E-selectin, VCAM-1, and ICAM-1 play essential roles in tumor cell arrest and extravasation into the hepatic parenchyma ${ }^{[52]}$. In particular, E-selectin facilitates diapedesis of tumor cells and subsequent invasion into the hepatic parenchyma. Invasion of tumor cells into the extra-sinusoidal space triggers the recruitment of HSCs and macrophages into the tumors. These macrophages are polarized by IL- 4 and IL- 13 towards M2 type macrophages expressing arginase- $1^{[48]}$ [Figure 3B]. Recruited HSCs release growth factors, cytokines, and matrix metalloproteinases (MMPs), and increase production of collagen. As a result, recruitment of vascular endothelial cells, assembly and turnover of extracellular matrix, and proliferation tumor cells are promoted. Tumor cells also produce VEGF to promote angiogenesis ${ }^{[47]}$ [Figure $3 \mathrm{C}$ ]. Hepatocytes contribute to fibrosis and neovascularization through secretion of IGF-1 and IGF-2, factors that promote HSC recruitment and activation. IGF-1 can also directly enhance tumor cell growth.

In addition to interacting with various residential cells in the liver, MDSCs are recruited to tumor sites in response to mediators released by tumor and/or resident hepatic cells. There are two different types of MDSC: polymorphonuclear MDSC (PMN-MDSC) and monocytic MDSC (M-MDSC). In the tumor sites, M-MDSCs are more prominent than PMN-MDSC, and M-MDSC rapidly differentiate to tumor-associated macrophage (TAM) to enhance tumor growth. $\mathrm{CD}^{+}{ }^{+} /$ CD163 ${ }^{+}$TAMs are observed in metastatic UM in the liver ${ }^{[49]}$. MDSCs produce immunosuppressive cytokines, such as IL-10 and TGF- $\beta$, and induce Tregs ${ }^{[53]}$. Subsequently, immunological equilibrium between tumor cells and host immune responses is shifted to the escape (growth) phase [Figure 3D]. More vascular endothelial cells are subsequently recruited to the tumor site and the tumors become further vascularized. Eventually, the vascularization of tumor results in rapid growth of metastasis.
Recently, microscopic investigation on inflammatory cells in advanced metastatic uveal melanoma tissue specimens was reported by Coupland's group ${ }^{[49]}$. They reported that $\mathrm{CD}^{+} \mathrm{T}$ lymphocytes were noted both within tumor and surrounding tissues. Of note, $\mathrm{CD} 8^{+}$ T lymphocytes were "few" in number within metastatic UM and were predominantly seen peritumorally at the tumor/normal liver interface. In contrast, $\mathrm{CD}^{+} \mathrm{T}$ lymphocytes showed a high perivascular density within melanoma. The characteristics of $\mathrm{CD}^{+} \mathrm{T}$ cells were not further investigated; however, it is possible that these $\mathrm{CD}^{+} \mathrm{T}$ cells might be Treg cells recruited from the peripheral circulation. Furthermore, $\mathrm{CD}^{+} 8^{+}$and $\mathrm{CD} 163^{+}$ TAMs of "indeterminate" morphology were observed in metastatic UM, suggesting the presence of the protumorigenic M2 phenotype. It has also been reported that tumor infiltrating $T$ cells obtained from metastatic UM were difficult to expand ex-vivo despite the lack of PD-L1 expression in tumor tissues ${ }^{[54]}$. Lack of PD-L1 expression by metastatic UM cells and marginalization of $\mathrm{CD}^{+} \mathrm{T}$ cells suggests an impaired anti-tumor immune response in metastatic UM.

Grossniklaus et al. ${ }^{[38]}$ proposed two growth patterns of hepatic metastasis: "infiltrative" and "nodular". They hypothesized that primary UM cells, expressing high levels of c-Met and/or CXCR4, aggregate in the liver which contains HGF and CXCL12. These metastatic UM cells have a CD133+ tumor stem cell-like phenotype, and give rise to the infiltrative or nodular growth patterns depending on whether the tumor is in the sinusoidal space (infiltrative) or periportal area (nodular). The infiltrative growth pattern showed cell growth within the sinusoidal space. The nodular growth pattern predominantly contained nodules of tumor that effaced, rather than infiltrated, the adjacent hepatocytes. Hepatic metastasis with infiltrative pattern showed the lack of VEGF protein in the tumor, but tumor cells induce MMP9 expression in monocytes and dissect through the tissue planes and creates "pseudosinusoidal spaces". On the other hand, UM cells that metastasize to the periportal areas in the hepatic triadcoopt the portal venules for nutrition and hypoxia resulting in MMP production and VEGF expression for angiogenesis. The role of the immune system in development of these two growth patterns needs to be further investigated.

\section{CURRENT IMMUNOTHERAPIES FOR METASTATIC UVEAL MELANOMA}

The major difference between $\mathrm{CM}$ and $\mathrm{UM}$ is the low mutational burden in UM compared to the high mutational burden in $\mathrm{CM}^{[19]}$. Metastatic UM is highly resistant to traditional systemic chemotherapies, and 

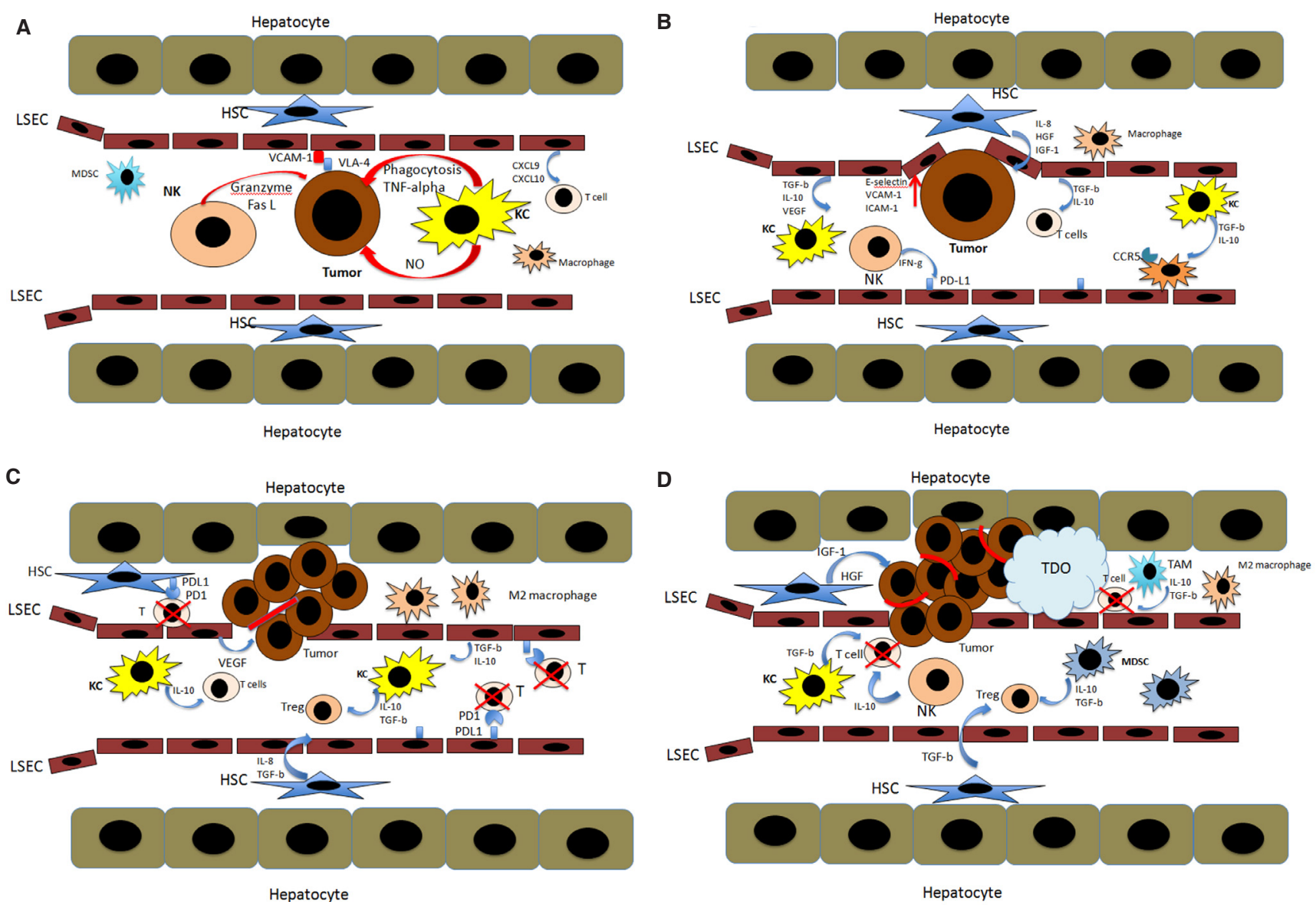

Figure 3: Liver immune microenvironment and tumor growth. A: immune attack on circulating tumor cells. Circulating tumor cells entering the sinusoidal area are attacked by immune cells in the sinusoid, especially Kupffer cells and NK cells. These cells eliminate tumor cells via phagocytosis, cytotoxic granules, death-receptor pathways, nitric oxide, or ROS; B: extravasation of tumor cells into the hepatic parenchyma. Following firm attachment to LSEC via adhesion molecules such as E-selection, VCAM-1, and ICAM-1, tumor cells escape from the sinusoidal space and invade into the extrasinusoidal space, which is rich in various growth factors such as HGF and IGF-1; C: remodeling of hepatic parenchyma and angiogenic sprouting. Tumor cell invasion into the extrasinusoidal space triggers HSC and M2 macrophage recruitment into the tumors and increases production of collagen in and around hepatic metastases. HSC recruited into the metastases as myofibroblasts release growth factors, cytokines, and MMPs. IL-8 produced by HSC induces the expression of VEGFR2 and VEGF on endothelial cells and mediates autocrine and paracrine stimulation of vascular endothelium; D: rapid growth of hepatic metastasis. Vascular endothelial cells are further recruited to the tumor site and tumors become further vascularized. The vascularization of tumor results in rapid growth of metastasis. Local production of Th-2 type cytokines, deprivation of tryptophan, and elimination of activated T cells via PD-L/PD-L1 interaction result in non-T cell inflamed immune microenvironment in the hepatic metastasis. CXCR9: chemokine (C-X-C motif) ligand 9; CXCR10: chemokine (C-X-C motif) ligand 10; CCR5: C-C chemokine receptor 5; Fas L: fas ligand; HSC: hepatic stellate cell; HGF: hepatocyte growth factor; IL-6: interleukin 6; IL-8: interleukin 8; IL-10: interleukin 10; IFN- $\gamma$ : interferon gamma; IGF1: insulin growth factor-1; KC: kupffer cell; LSEC: liver sinusoidal endothelial cell; NO: nitric oxide; PD 1: programmed death 1; PD-L1: programmed death ligand 1; TDO: tryptophan 2,3 dioxtgenase; TGF- $\beta$ : transforming growth factor beta; T reg: regulatory t Cell; VCAM-1: vascular cell adhesion protein 1; VEGF: vascular endothelial growth factor; VLA-4: very late antigen 4; ROS: reactive oxygen species

currently approved signal inhibitors for CM do not work for metastatic UM. In addition, the liver is one of the most tolerogenic immune microenvironments, especially in regard to the $\mathrm{T}$ cell immune system. Taken together, metastatic UM is one of the most challenging tumors and convincing survival benefit of systemic and local treatments remains to be been seen.

There have been several clinical trials using immunotherapy for metastatic UM [Table 1]. These clinical trials have provided important insights into the immune microenvironment of metastatic UM and have identified a direction for future immunotherapy truly for metastatic UM.

\section{LOCOREGIONAL TREATMENT}

The liver is the first and dominant site of metastasis in $\mathrm{UM}$, therefore it is reasonable to consider locoregional immunotherapy to directly destroy the tumor and provide tumor-related antigens to the systemic immune system. We have developed one such approach called, "immunoembolization (IE)". This consists of embolization of the tumor-feeding hepatic artery by 
Table 1: Immunotherapy clinical trials in metastatic uveal melanoma

\begin{tabular}{|c|c|c|c|c|}
\hline Study & Phase & Identifier & $\begin{array}{l}\text { Targets and } \\
\text { approaches }\end{array}$ & Status \\
\hline Nivolumab and ipilimumab in treating patients with MUM & Phase II & NCT01585194 & $\begin{array}{l}\text { PD-1 and } \\
\text { CTLA-4, MoAb }\end{array}$ & Recruiting \\
\hline Pembrolizumab in treating patients with advanced uveal melanoma & Phase II & NCT02359851 & PD-1, MoAb & $\begin{array}{l}\text { Ongoing but not } \\
\text { recruiting }\end{array}$ \\
\hline $\begin{array}{l}\text { Glembatumumab vedotin in treating patients with metastatic or locally } \\
\text { recurrent uveal melanoma }\end{array}$ & Phase II & NCT02363283 & gpNMB, ADC & Recruiting \\
\hline $\begin{array}{l}\text { A study of the intra-patient escalation dosing regimen with IMCgp } 100 \text { in } \\
\text { patients with advanced uveal melanoma }\end{array}$ & Phase I & NCT02570308 & $\begin{array}{l}\text { gp100, TCR-CD3 } \\
\text { Ab fusion protein }\end{array}$ & Recruiting \\
\hline $\begin{array}{l}\text { Yttrium90, ipilimumab and nivolumab for uveal melanoma with liver } \\
\text { metastases }\end{array}$ & $\begin{array}{l}\text { Phase I, } \\
\text { Phase II }\end{array}$ & NCT02913417 & $\begin{array}{l}\text { PD-1 and CTLA- } 4 \\
\text { + radiospheres }\end{array}$ & Recruiting \\
\hline Dendritic cells plus autologous tumor RNA in uveal melanoma & Phase III & NCT01983748 & DC plus mRNA & Recruiting \\
\hline $\begin{array}{l}\text { Immunotherapy using tumor infiltrating lymphocytes for patients with } \\
\text { metastatic ocular melanoma }\end{array}$ & Phase II & NCT01814046 & TIL & $\begin{array}{l}\text { Ongoing but not } \\
\text { recruiting }\end{array}$ \\
\hline $\begin{array}{l}\text { Trial of nivolumab in combination with ipilimumab in subjects with } \\
\text { previously untreated metastatic uveal melanoma (GEM1402) }\end{array}$ & Phase II & NCT02626962 & $\begin{array}{l}\text { PD-1 and } \\
\text { CTLA-4 }\end{array}$ & $\begin{array}{l}\text { Ongoing but not } \\
\text { recruiting }\end{array}$ \\
\hline $\begin{array}{l}\text { Epacadostat and vaccine therapy in treating patients with Stage III-IV } \\
\text { melanoma }\end{array}$ & Phase II & NCT01961115 & $\begin{array}{l}\text { IDO1 inhibitor + } \\
\text { MELITAC } 12.1 \\
\text { Vaccine }\end{array}$ & $\begin{array}{l}\text { Ongoing but not } \\
\text { recruiting }\end{array}$ \\
\hline
\end{tabular}

MUM: metastatic uveal melanoma; MoAb: monoclonal antibody; ADC: antibody-drug conjugate; TIL: tumor infiltrating lymphocytes; DC: dendritic cells; IDO: indoleamine 2, 3-dioxygenase. As of May 2017 [Clinical Trials. gov].

gelatin sponge particles following arterial infusion of GM-CSF emulsified in ethiodized oil. In theory, metastatic UM cells will be killed by the ischemic effect of embolization; GM-CSF stimulates APCs and promotes uptake of tumor antigens, leading to the induction of $T$ cell activation in the liver and at a secondary lymph node. This approach could lead to the development of systemic immunity against melanoma and delay development and progression of extra-hepatic metastasis. This concept was subsequently investigated in a clinical trial setting. Compared with chemoembolization with 1,3-bis (2-chloroethyl)-1-nitrosourea (CE), IE induced significantly better overall survival (OS) (20.4 vs. 9.8 months, $P=0.005$ ) and systemic progression free survival (PFS) (12.4 vs. 4.8 months, $P=0.001)^{[55]}$.

In subsequent randomized double-blinded clinical trials, IE was compered with embolization of hepatic tumor with normal saline solution with ethiodized oil, "bland embolization (BE)"[56]. Overall survival was 21.5 months (95\% Cl: 18.5-24.8 months) with IE and 17.2 months (95\% Cl: 11.9-22.4 months) with BE. The degree of proinflammatory cytokine production was more robust after IE. TNF- $\alpha$, IL-6, and IL-8 levels in serum were increased with IE $1 \mathrm{~h}$ and $18 \mathrm{~h}$ after the embolization procedures. On the other hand, IL- 6 and IL-8 levels in serum in BE were mildly increased $18 \mathrm{~h}$ after the procedures. The higher degree of cytokine release after IE was correlated with longer time to "systemic" extrahepatic progression. In the IE group, higher IL-6 levels at $1 \mathrm{~h}(P<0.001)$ and IL-8 levels at $18 \mathrm{~h}$ after the procedure $(P<0.001)$ were significant predictors of longer systemic PFS. We are currently in the process of initiating a new phase 2 study, in which IE will be combined with the immune checkpoint inhibitors, ipilimumab and nivolumab.

Since hepatic metastasis is life-limiting in the majority of patients and the induction of anti-tumor response by traditional chemotherapies or immunotherapies is difficult, various liver-directed treatments have been investigated including percutaneous hepatic perfusion with melphalan, intrahepatic arterial infusion with fotemustine. The impact of these liver-directed treatments on tumor immune microenvironment in the liver remains to be investigated.

\section{SYSTEMIC IMMUNOTHERAPY}

\section{Immune checkpoint blockade}

Development and approval of immune-modulatory antibodies against cytotoxic $T$ lymphocyte associated antigen 4 (CTLA-4) and PD-1/PD-L1 resulted in aparadigm shift in the treatment of metastatic $\mathrm{CM}^{[57-59]}$ and provided hope for patients with this disease. Unfortunately, this new approach did not improve the outcome of metastatic UM. Disappointing response rates have been reported with anti-CTLA-4 antibody as well as with anti-PD-1/PD-L1 antibody treatments in metastatic $\mathrm{UM}^{[60,61]}$. In the retrospective collection of data on 82 assessable UM patients who received ipilimumab, the fully human monoclonal antibody against CTLA-4, at $3 \mathrm{mg} / \mathrm{kg}$, every 3 weeks for a maximum of 4 doses, 4 $(5 \%)$ had an immune-related objective response and 24 $(29 \%)$ had immune-related stable disease lasting $\geq 3$ months. With a median follow-up of 5.6 months, 
median OS was 6.0 months and median PFS was 3.6 months. The 1 -year rates of OS and PFS were $31 \%$ and $11 \%$, respectively ${ }^{[61]}$.

Another retrospective study including 34 patients who received $3 \mathrm{mg} / \mathrm{kg}$ ipilimumab and 5 patients who received $10 \mathrm{mg} / \mathrm{kg}$ ipilimumab showed 1 complete response (CR) and 1 late partial response $(P R)$ for an immune-related response rate of $5.1^{[62]}$. The OS from the first dose of ipilimumab was 9.6 months $(95 \% \mathrm{Cl}$ : 6.313.4 months). Survival ranged from 1.6 to 41.6 months in this study. Retrospective investigation of 56 patients treated with anti-PD-1 or PD-L1 antibodies also showed disappointing results ${ }^{[60]}$. Among 56 UM patients, objective tumor responses were observed in only 2 patients for OS of $3.6 \%$ (95\% Cl: $1.8-22.2 \%)$. Stable disease ( $\geq 6$ months) was observed in 5 patients. The median PFS was 2.6 months (95\% Cl: 2.4-2.8 months), and the OS was 7.6 months ( $95 \% \mathrm{Cl}$ : 0.7-14.6 months). The result may be correlated with low expression of PDL1 in metastatic UM, compared to that of non-hepatic metastatic $\mathrm{CM}^{[63]}$. It is of note that a poor response to anti-PD-1 antibody therapy has also been reported in CM patients with hepatic metastasis ${ }^{[64]}$. This further supports the hypothesis that the liver immune microenvironment itself hampers T-cell immune response against cancer cells.

\section{Adoptive immunotherapy using tumor-infiltrating $T$ cells}

Tumor-infiltrating T cells (TIL) treatment has been highly successful in metastatic UM with durable response and regression of bulky metastasis. In a study at National Cancer Institute (NCT01814046), 21 metastatic UM patients who were HLA-A2 positive were treated with TIL therapy in phase II clinical trial[65,66]. Seven of 20 evaluable patients showed objective tumor regression including 6 patients with $\mathrm{PR}$ and one patient with $\mathrm{CR}$, ongoing at 21 months post therapy. No significant difference was seen among responders and non-responders in terms of mutation burden in tumors. On the other hand, TIL products with either less than $3 \%$ tumorreactive $\mathrm{T}$ cells, less than $2 \times 10^{9}$ tumor-reactive $\mathrm{T}$ cells, or less than $100 \mathrm{pg} / \mathrm{mL}$ of tumor-induced IFN-y release yielded poor clinical responses ${ }^{[6]}$. This study indicated that adoptive transfer of autologous TILs can mediate objective tumor regression in patients with metastatic UM.

\section{DC vaccine}

Melanocyte-associated proteins including gp100, MART-1, tyrosinase, and TRP-1 were also expressed in the majority of human $\mathrm{UM}^{[67]}$. These tumor- associated antigens constitute an appropriate target for immunotherapy for metastatic disease. DCs are antigen-presenting cells with the unique ability to activate naive $T$ cells, and hence are suitable for inducing immunologic antitumor responses. A group from the Netherlands treated 14 metastatic UM patients with therapeutic DC vaccines loaded with gp100 and tyrosinase. Patients were required to have HLA-A $02: 01$ phenotype or HLA-DRB*01:04 and needed to have metastatic UM expressing gp100 and tyrosinase. All patients were vaccinated with autologous DCs loaded with gp100 and tyrosinase in various ways (mutated or wild type peptides, or mRNA), 3 times, biweekly. One to 2 weeks after the last vaccination, a skin test was performed. In the absence of disease recurrence, patients received a maximum of 2 maintenance cycles of vaccine at 6 -month intervals. T cells specific for gp100 and tyrosinase were detected by tetramer assay after DC vaccination in $4(29 \%)$ of 14 patients. DCvaccinated patients with metastatic disease showed a median overall survival of 19.2 months. No serious treatment-related adverse events (common toxicity criteria grade 3 or 4 ) were observed. Clinically, no regression of metastasis was observed. Ten patients showed stable disease at the first evaluation point, 3 months after start of vaccination, but 7 patients subsequently progressed before the first maintenance cycle of vaccine was started at 6 months. Seven (50\%) patients survived more than 2 years after start of DC vaccination for metastatic UM ${ }^{[68]}$. The efficacy of this therapeutic DC vaccine remains to be investigated in a large prospective study with a more uniform antigenloading method to DC.

\section{TCR and anti-CD3 antibody fusion protein}

IMCgp100 is a fusion protein containing gp100-specific $T$ cell receptor (HLA-A*02:01) and anti-CD3 scFv. IMCgp100 binds to UM cells that express gp100 peptides on $\mathrm{MHC}$ Class I and then tags $\mathrm{CD}^{+} \mathrm{T}$ cells to the other end via anti-CD3 antibody. Soluble TCRs have been engineered and modified to possess extremely high affinity to gp100 peptides on HLA-A*02:01 molecules. The early phase clinical studies showed encouraging results ${ }^{[69,70]}$ and a pivotal large-scale randomized phase 2 study for metastatic UM is planned to start.

\section{Antibody target glycoprotein NMB}

Glembatumumabvedotin (also known as CDX-011 and CR011-vcMMAE) is an antibody-drug conjugate (ADC) that targets cancer cells expressing transmembrane glycoprotein NMB (gpNMB). It is a fusion molecule containing fully-human IgG2 monoclonal antibody against gpNMB and the cytotoxic drug monomethyl auristatin $\mathrm{E}$ (MMAE). The anti-gpNMB antibody binds to gpNMB expressing tumor cells and, upon internalization, 
the antibody releases MMAE, a potent cytotoxic agent. gpNMB is overexpressed by multiple tumors including melanoma and breast cancer. Eighteen of 21 primary UM tissue specimens $(85.7 \%)$ evaluated by immunohistochemical analysis (IHC) expressed gpNMB in $10-90 \%$ of tumor cells with variable intensity ${ }^{[71]}$. A phase 2 clinical study for Glembatumumab vedotin in metastatic or locally recurrent UM (NCT02363283) has been recently concluded ${ }^{[72]}$. The final results are awaited.

\section{CONCLUSION}

There is no standard care for the treatment of patients with metastatic UM. The effectiveness of treatments for metastatic UM seems to be very limited, and induction of immunity against UM cells may be the major challenge. We are just beginning to understand the immune suppressive pathways involved in metastatic UM and their tumor microenvironment. As we described in this review article, immune reactions can be generated against cancer cells under specific circumstances such as the presence of cognitive antigens, an increasing level of APCs, high affinity of interactive TCR, and depletion of inhibitory immune cells or molecules in the liver. Considering potential pre-existing immune tolerance against UM cells, low mutational burden, and an immune-modulating microenvironment in the liver, mechanical perturbation of hepatic metastasis with or followed by immunostimulatory molecules would be a reasonable approach. Alternatively, the usage of ex-vivo activated tumor-specific T cells or mimicking approaches such as bispecific fusion proteins would be a promising approach against metastatic UM as suggested by on-going clinical trials. Inhibitors of key signal pathways unique to metastatic UM might also be helpful in increasing immunogenicity of UM cells, which in turn might improve the efficacy of currently available immune checkpoint blockades. Further collaboration between basic immunology researchers and clinical scientists is required for the development of more effective immunotherapy strategies against metastatic UM.

\section{DECLARATIONS}

\section{Authors' contributions}

Drafting and writing the manuscript: M. Terai

Manuscript's conception, revision and supervised: M.J. Mastrangleo, T. Sato

\section{Financial support and sponsorship} None.

\section{Conflicts of interest}

There are no conflicts of interest.

\section{Patient consent}

Not applicable.

\section{Ethics approval}

Not applicable.

\section{REFERENCES}

1. Kaliki S, Shields CL, Shields JA. Uveal melanoma: estimating prognosis. Indian J Ophthalmol 2015;63:93-102.

2. Collaborative Ocular Melanoma Study Group. Assessment of metastatic disease status at death in 435 patients with large choroidal melanoma in the Collaborative Ocular Melanoma Study (COMS): COMS report no. 15. Arch Ophthalmol 2001;119:670-6.

3. Ewens KG, Kanetsky PA, Richards-Yutz J, Purrazzella J, Shields CL, Ganguly T, Ganguly A. Chromosome 3 status combined with BAP1 and EIF1AX mutation profiles are associated with metastasis in uveal melanoma. Invest Ophthalmol Vis Sci 2014;55:5160-7.

4. Damato B, Eleuteri A, Taktak AF, Coupland SE. Estimating prognosis for survival after treatment of choroidal melanoma. Prog Retin Eye Res 2011:30:285-95.

5. Singh AD, Turell ME, Topham AK. Uveal melanoma: trends in incidence, treatment, and survival. Ophthalmology 2011;118:1881-5.

6. Malina HZ, Martin XD. Indoleamine 2,3-dioxygenase: antioxidant enzyme in the human eye. Graefes Arch Clin Exp Ophthalmol 1996;234:457-62.

7. Bronkhorst IH, Vu TH, Jordanova ES, Luyten GP, Burg SH, Jager MJ. Different subsets of tumor-infiltrating lymphocytes correlate with macrophage influx and monosomy 3 in uveal melanoma. Invest Ophthalmol Vis Sci 2012;53:5370-8.

8. Bronkhorst IH, Ly LV, Jordanova ES, Vrolijk J, Versluis M, Luyten GP, Jager MJ. Detection of M2-macrophages in uveal melanoma and relation with survival. Invest Ophthalmol Vis Sci 2011;52:643-50.

9. Makitie T, Summanen P, Tarkkanen A, Kivela T. Tumor-infiltrating macrophages $(\mathrm{CD} 68(+)$ cells $)$ and prognosis in malignant uveal melanoma. Invest Ophthalmol Vis Sci 2001;42:1414-21.

10. Mougiakakos D, Johansson CC, Trocme E, All-Ericsson C, Economou MA, Larsson O, Seregard S, Kiessling R. Intratumoral forkhead box P3-positive regulatory $\mathrm{T}$ cells predict poor survival in cyclooxygenase2-positive uveal melanoma. Cancer 2010;116:2224-33.

11. Vetter CS, Lieb W, Brocker EB, Becker JC. Loss of nonclassical $\mathrm{MHC}$ molecules MIC-A/B expression during progression of uveal melanoma. Br J Cancer 2004;91:1495-9.

12. Elinav E, Nowarski R, Thaiss CA, Hu B, Jin C, Flavell RA. Inflammation-induced cancer: crosstalk between tumours, immune cells and microorganisms. Nat Rev Cancer 2013;13:759-71.

13. Vidal-Vanaclocha F. The prometastatic microenvironment of the liver. Cancer Microenviron 2008;1:113-29.

14. Bakalian S, Marshall JC, Logan P, Faingold D, Maloney S, Di Cesare S, Martins C, Fernandes BF, Burnier MN Jr. Molecular pathways mediating liver metastasis in patients with uveal melanoma. Clin Cancer Res 2008;14:951-6.

15. van den Bosch T, Koopmans AE, Vaarwater J, van den Berg M, de Klein A, Verdijk RM. Chemokine receptor CCR7 expression predicts poor outcome in uveal melanoma and relates to liver metastasis whereas expression of CXCR4 is not of clinical relevance. Invest Ophthalmol Vis Sci 2013;54:7354-61.

16. Li H, Alizadeh H, Niederkorn JY. Differential expression of chemokine 
receptors on uveal melanoma cells and their metastases. Invest Ophthalmol Vis Sci 2008;49:636-43.

17. Yoshida M, Selvan S, McCue PA, DeAngelis T, Baserga R, Fujii A, Rui $\mathrm{H}$, Mastrangelo MJ, Sato T. Expression of insulin-like growth factor-1 receptor in metastatic uveal melanoma and implications for potential autocrine and paracrine tumor cell growth. Pigment Cell Melanoma Res 2014;27:297-308.

18. Economou MA, All-Ericsson C, Bykov V, Girnita L, Bartolazzi A, Larsson O, Seregard S. Receptors for the liver synthesized growth factors IGF-1 and HGF/SF in uveal melanoma: intercorrelation and prognostic implications. Invest Ophthalmol Vis Sci 2005;46:4372-5.

19. Helgadottir H, Hoiom V. The genetics of uveal melanoma: current insights. Appl Clin Genet 2016;9:147-55.

20. van den Bosch T, Kilic E, Paridaens D, de Klein A. Genetics of uveal melanoma and cutaneous melanoma: two of a kind? Dermatol Res Pract 2010;2010:360136.

21. Harbour JW, Onken MD, Roberson ED, Duan S, Cao L, Worley LA, Council ML, Matatall KA, Helms C, Bowcock AM. Frequent mutation of BAP1 in metastasizing uveal melanomas. Science 2010;330:1410-3.

22. Kalirai H, Dodson A, Faqir S, Damato BE, Coupland SE. Lack of BAP1 protein expression in uveal melanoma is associated with increased metastatic risk and has utility in routine prognostic testing. Br J Cancer 2014;111:1373-80.

23. McCarthy C, Kalirai H, Lake SL, Dodson A, Damato BE, Coupland SE. Insights into genetic alterations of liver metastases from uveal melanoma. Pigment Cell Melanoma Res 2016;29:60-7.

24. Trolet J, Hupé P, Huon I, Lebigot I, Decraene C, Delattre O, SastreGarau X, Saule S, Thiéry JP, Plancher C, Asselain B, Desjardins L, Mariani P, Piperno-Neumann S, Barillot E, Couturier J. Genomic profiling and identification of high-risk uveal melanoma by array $\mathrm{CGH}$ analysis of primary tumors and liver metastases. Invest Ophthalmol Vis Sci 2009;50:2572-80.

25. Van den Eynden GG, Majeed AW, Illemann M, Vermeulen PB, Bird NC, Hoyer-Hansen G, Eefsen RL, Reynolds AR, Brodt P. The multifaceted role of the microenvironment in liver metastasis: biology and clinical implications. Cancer Res 2013;73:2031-43.

26. Bai L, Mao GP, Cao CP. Effects of inflammatory cytokines on the recurrence of liver cancer after an apparently curative operation. J Dig Dis 2007;8:154-9.

27. Martin-Padura I, Mortarini R, Lauri D, Bernasconi S, Sanchez-Madrid F, Parmiani G, Mantovani A, Anichini A, Dejana E. Heterogeneity in human melanoma cell adhesion to cytokine activated endothelial cells correlates with VLA-4 expression. Cancer Res 1991;51:2239-41.

28. Zhu B, Lin N, Zhang M, Zhu Y, Cheng H, Chen S, Ling Y, Pan W, Xu R. Activated hepatic stellate cells promote angiogenesis via interleukin-8 in hepatocellular carcinoma. J Transl Med 2015;13:365.

29. Racanelli V, Rehermann B. The liver as an immunological organ. Hepatology 2006;43:S54-62.

30. Jenne CN, Kubes P. Immune surveillance by the liver. Nat Immunol 2013;14:996-1006

31. Naito M, Hasegawa G, Takahashi K. Development, differentiation, and maturation of Kupffer cells. Microsc Res Tech 1997;39:350-64.

32. Bilzer M, Roggel F, Gerbes AL. Role of Kupffer cells in host defense and liver disease. Liver Int 2006;26:1175-86.

33. Kimura Y, Inoue A, Hangai S, Saijo S, Negishi H, Nishio J, Yamasaki $\mathrm{S}$, Iwakura Y, Yanai H, Taniguchi T. The innate immune receptor Dectin-2 mediates the phagocytosis of cancer cells by Kupffer cells for the suppression of liver metastasis. Proc Natl Acad Sci USA 2016;113:14097-102.

34. Yin C, Evason KJ, Asahina K, Stainier DY. Hepatic stellate cells in liver development, regeneration, and cancer. J Clin Invest 2013;123:190210 .

35. Cheng H, Terai M, Kageyama K, Ozaki S, McCue PA, Sato T, Aplin
AE. Paracrine effect of NRG1 and HGF drives resistance to MEK inhibitors in metastatic uveal melanoma. Cancer Res 2015;75:273748.

36. Martin D, Galisteo R, Gutkind JS. CXCL8/IL8 stimulates vascular endothelial growth factor (VEGF) expression and the autocrine activation of VEGFR2 in endothelial cells by activating NFkappaB through the CBM (Carma3/Bcl10/Malt1) complex. J Biol Chem 2009;284:6038-42.

37. Norris CA, He M, Kang LI, Ding MQ, Radder JE, Haynes MM, Yang Y, Paranjpe S, Bowen WC, Orr A,Michalopoulos GK, Stolz DB, Mars WM. Synthesis of IL-6 by hepatocytes is a normal response to common hepatic stimuli. PLoS One 2014;9:e96053.

38. Grossniklaus HE, Zhang Q, You S, McCarthy C, Heegaard S, Coupland SE. Metastatic ocular melanoma to the liver exhibits infiltrative and nodular growth patterns. Hum Pathol 2016;57:165-75.

39. Male V. Liver-resident NK cells: the human factor. Trends Immunol 2017;38:307-9.

40. Bandyopadhyay K, Marrero I, Kumar V. NKT cell subsets as key participants in liver physiology and pathology. Cell Mol Immunol 2016;13:337-46.

41. Tiegs G, Lohse AW. Immune tolerance: what is unique about the liver J Autoimmun 2010;34:1-6.

42. Franceschini D, Paroli M, Francavilla V, Videtta M, Morrone S, Labbadia G, Cerino A, Mondelli MU, Barnaba V. PD-L1 negatively regulates CD4+CD25+Foxp3+ Tregs by limiting STAT5 phosphorylation in patients chronically infected with HCV. J Clin Invest 2009;119:551-64.

43. Pilotte L, Larrieu P, Stroobant V, Colau D, Dolusic E, Frederick R, De Plaen E, Uyttenhove C, Wouters J, Masereel B,Van den Eynde BJ.Reversal of tumoral immune resistance by inhibition of tryptophan 2,3-dioxygenase. Proc Natl Acad Sci U S A 2012;109:2497-502.

44. Platten M, von Knebel Doeberitz N, Oezen I, Wick W, Ochs K Cancer immunotherapy by targeting IDO1/TDO and their downstream effectors. Front Immunol 2014;5:673.

45. Crispe IN. Hepatic T cells and liver tolerance. Nat Rev Immunol 2003;3:51-62.

46. Schildberg FA, Sharpe AH, Turley SJ. Hepatic immune regulation by stromal cells. Curr Opin Immunol 2015;32:1-6.

47. Ozaki S, Vuyyuru R, Kageyama K, Terai M, Ohara M, Cheng H, Manser T, Mastrangelo MJ, Aplin AE, Sato T. Establishment and characterization of orthotopic mouse models for human uveal melanoma hepatic colonization. Am J Pathol 2016;186:43-56.

48. Robinson MW, Harmon C, O'Farrelly C. Liver immunology and its role in inflammation and homeostasis. Cell Mol Immunol 2016;13:267-76.

49. Krishna Y, McCarthy C, Kalirai H, Coupland SE. Inflammatory cell infiltrates in advanced metastatic uveal melanoma. Hum Pathol 2017;66:159-66

50. Vidal-Vanaclocha F, Fantuzzi G, Mendoza L, Fuentes AM, Anasagast MJ, Martín J, Carrascal T, Walsh P, Reznikov LL, Kim SH, Novick D, Rubinstein M, Dinarello CA. IL-18 regulates IL-1beta-dependent hepatic melanoma metastasis via vascular cell adhesion molecule-1. Proc Natl Acad Sci U S A 2000;97:734-9.

51. Tecchio C, Micheletti A, Cassatella MA. Neutrophil-derived cytokines: facts beyond expression. Front Immunol 2014;5:508.

52. Auguste P, Fallavollita L, Wang N, Burnier J, Bikfalvi A, Brodt P. The host inflammatory response promotes liver metastasis by increasing tumor cell arrest and extravasation. Am J Pathol 2007;170:1781-92.

53. Kumar V, Patel S, Tcyganov E, Gabrilovich DI. The nature of myeloidderived suppressor cells in the tumor microenvironment. Trends Immunol 2016;37:208-20.

54. Qin Y, Petaccia de Macedo M, Reuben A, Forget MA, Haymaker C, Bernatchez C, Spencer CN, Gopalakrishnan V, Reddy S, Cooper ZA,Fulbright OJ, Ramachandran R, Wahl A, Flores E, Thorsen ST, Tavera RJ, Conrad C, Williams MD, Tetzlaff MT, Wang WL, Gombos 
DS,Esmaeli B, Amaria RN, Hwu P, Wargo JA, Lazar AJ, Patel SP. Parallel profiling of immune infiltrate subsets in uveal melanoma versus cutaneous melanoma unveils similarities and differences: a pilot study. Oncoimmunology 2017;6:e1321187.

55. Yamamoto A, Chervoneva I, Sullivan KL, Eschelman DJ, Gonsalves CF, Mastrangelo MJ, Berd D, Shields JA, Shields CL, Terai M, Sato T. High-dose immunoembolization: survival benefit in patients with hepatic metastases from uveal melanoma. Radiology 2009;252:290-8.

56. Valsecchi ME, Terai M, Eschelman DJ, Gonsalves CF, Chervoneva I, Shields JA, Shields CL, Yamamoto A, Sullivan KL, Laudadio M, Berd D, Mastrangelo MJ, Sato T. Double-blinded, randomized phase II study using embolization with or without granulocyte-macrophage colony-stimulating factor in uveal melanoma with hepatic metastases. J Vasc Interv Radiol 2015;26:523-32.e2.

57. Hodi FS, O’Day SJ, McDermott DF, Weber RW, Sosman JA, Haanen JB, Gonzalez R, Robert C, Schadendorf D, Hassel JC, Akerley W, van den Eertwegh AJ, Lutzky J, Lorigan P, Vaubel JM, Linette GP, Hogg D, Ottensmeier CH, Lebbé C, Peschel C, Quirt I, Clark JI, Wolchok JD, Weber JS, Tian J, Yellin MJ, Nichol GM, Hoos A, Urba WJ. Improved survival with ipilimumab in patients with metastatic melanoma. N Engl J Med 2010;363:711-23.

58. Robert C, Thomas L, Bondarenko I, O'Day S, Weber J, Garbe C, Lebbe C, Baurain JF, Testori A, Grob JJ, Davidson N, Richards J, Maio M, Hauschild A, Miller WH Jr, Gascon P, Lotem M, Harmankaya K, Ibrahim R, Francis S, Chen TT, Humphrey R, Hoos A, Wolchok JD. Ipilimumab plus dacarbazine for previously untreated metastatic melanoma. N Engl J Med 2011;364:2517-26.

59. Topalian SL, Sznol M, McDermott DF, Kluger HM, Carvajal RD, Sharfman WH, Brahmer JR, Lawrence DP, Atkins MB, Powderly JD, Leming PD, Lipson EJ, Puzanov I, Smith DC, Taube JM, Wigginton JM, Kollia GD, Gupta A, Pardoll DM, Sosman JA, Hodi FS. Survival, durable tumor remission, and long-term safety in patients with advanced melanoma receiving nivolumab. J Clin Oncol 2014;32:1020-30.

60. Algazi AP, Tsai KK, Shoushtari AN, Munhoz RR, Eroglu Z, Piulats JM, Ott PA, Johnson DB, Hwang J, Daud AI, Sosman JA, Carvajal RD, Chmielowski B, Postow MA, Weber JS, Sullivan RJ. Clinical outcomes in metastatic uveal melanoma treated with PD-1 and PD-L1 antibodies. Cancer 2016;122:3344-53.

61. Maio M, Danielli R, Chiarion-Sileni V, Pigozzo J, Parmiani G, Ridolfi R, De Rosa F, Del Vecchio M, Di Guardo L, Queirolo P, Picasso V, Marchetti P, De Galitiis F, Mandalà M, Guida M, Simeone E, Ascierto PA. Efficacy and safety of ipilimumab in patients with pre-treated, uveal melanoma. Ann Oncol 2013;24:2911-5.

62. Luke JJ, Callahan MK, Postow MA, Romano E, Ramaiya N, Bluth M, Giobbie-Hurder A, Lawrence DP, Ibrahim N, Ott PA, Flaherty KT, Sullivan RJ, Harding JJ, D’Angelo S, Dickson M, Schwartz GK, Chapman PB, Wolchok JD, Hodi FS, Carvajal RD. Clinical activity of ipilimumab for metastatic uveal melanoma: a retrospective review of the Dana-Farber Cancer Institute, Massachusetts General Hospital,
Memorial Sloan-Kettering Cancer Center, and University Hospital of Lausanne experience. Cancer 2013;119:3687-95.

63. Javed A, Arguello D, Johnston C, Gatalica Z, Orloff MM, Mastrangelo MJ, Sato T. Disparity in PD-L1 expression between metastatic uveal and cutaneous melanoma. J Clin Oncol 2016;ASCO 2016:abstract 9541.

64. Tumeh PC, Hellmann MD, Hamid O, Tsai KK, Loo KL, Gubens MA, Rosenblum M, Harview CL, Taube JM, Handley N, Khurana N, Nosrati A, Krummel MF, Tucker A, Sosa EV, Sanchez PJ, Banayan N, Osorio JC, Nguyen-Kim DL, Chang J, Shintaku IP, Boasberg PD, Taylor EJ,Munster PN, Algazi AP, Chmielowski B, Dummer R, Grogan TR, Elashoff D, Hwang J, Goldinger SM, Garon EB, Pierce RH, Daud A. Liver metastasis and treatment outcome with anti-PD-1 monoclonal antibody in patients with melanoma and NSCLC. Cancer Immunol Res 2017;5:417-24.

65. Chandran SS, Somerville RP, Yang JC, Sherry RM, Klebanoff CA, Goff SL, Wunderlich JR, Danforth DN, Zlott D, Paria BC, Sabesan AC, Srivastava AK, Xi L, Pham TH, Raffeld M, White DE, Toomey MA, Rosenberg SA, Kammula US. Treatment of metastatic uveal melanoma with adoptive transfer of tumour-infiltrating lymphocytes: a single-centre, two-stage, single-arm, phase 2 study. Lancet Oncol 2017; 18:792-802.

66. Rothermel LD, Sabesan AC, Stephens DJ, Chandran SS, Paria BC, Srivastava AK, Somerville R, Wunderlich JR, Lee CC, Xi L, Pham TH, Raffeld M, Jailwala P, Kasoji M, Kammula US. Identification of an immunogenic subset of metastatic uveal melanoma. Clin Cancer Res 2016;22:2237-49.

67. de Vries TJ, Trancikova D, Ruiter DJ, van Muijen GN. High expression of immunotherapy candidate proteins gp 100, MART-1, tyrosinase and TRP-1 in uveal melanoma. Br J Cancer 1998;78:1156-61.

68. Bol KF, Mensink HW, Aarntzen EH, Schreibelt G, Keunen JE, Coulie PG, de Klein A, Punt CJ, Paridaens D, Figdor CG, de Vries IJ.Long overall survival after dendritic cell vaccination in metastatic uveal melanoma patients. Am J Ophthalmol 2014;158:939-47.

69. Middleton MR, Corrie P, Sznol M, Infante J, Mulatero C, Evans J, Steven N, Krige D, Shingler WH, McGrath Y, Hassan NJ, Jakobsen BK. A phase I/IIa study of IMCgp100: partial and complete durable responses with a novel first-in-class immunotherapy for advanced melanoma. Cancer Res 2015;75:abstract CT106.

70. Sato T, Nathan PD, Hernandez-Aya LF, Sacco JJ, Orloff MM, Truscello J, McAlpine C, Hulstine A-M, Lanasa MC, Coughlin CM, Carvajal RD. Intra-patient escalation dosing strategy with IMCgp100 results in mitigation of T-cell based toxicity and preliminary efficacy in advanced uveal melanoma. J Clin Oncol 2017;ASCO 2017:abstract 9531.

71. Esmaeli B, Williams MD, Soheili A, Gombos DS, Simantov R. GPNMB expression in uveal melanomas: a potential for targeted therapy. Invest Ophthalmol Vis Sci 2009;50:3385.

72. Patel S, Lewis KD, Olencki T, Hernandez-Aya L, Joseph R, Williamson S, Chandra S, Shirai K, Moscow J. A Phase II Study of Glembatumumab Vedotin for Metastatic Uveal Melanoma. Avaliable from: http://www.melanomacongress.com/docs/2017 abstracts.pdf. [Last accessed on 23 Oct 2017] 